\title{
Influence of Inoculum Density of Verticillium dahliae on Root Discoloration of Horseradish
}

\author{
A. Khan, N. Atibalentja, and D. M. Eastburn, Department of Crop Sciences, University of Illinois at Urbana- \\ Champaign, 61801
}

\begin{abstract}
Khan, A., Atibalentja, N., and Eastburn, D. M. 2000. Influence of inoculum density of Verticillium dahliae on root discoloration of horseradish. Plant Dis. 84:309-315.

The relationship between inoculum density (number of microsclerotia per gram of air-dried soil) of Verticillium dahliae at the time of planting and the severity and incidence of root discoloration of horseradish at harvest was investigated in a 2-year study conducted in the greenhouse, microplots, and commercial production fields. The objective of the study was to develop a disease-forecast system that would assist growers in assessing the risk of the disease before planting horseradish in a particular field. Significant correlations were observed between inoculum density and severity and incidence of root discoloration in the greenhouse and microplots, although the form of the relationship varied with trials from linear to quadratic and negative exponential. No correlation was found between inoculum density of V. dahliae and severity and incidence of root discoloration in commercial production fields. In some fields with low inoculum densities, high ratings of severity and incidence of root discoloration were observed even with the partially resistant cultivar 769A. Conversely, in other fields with high inoculum densities, low ratings of severity and incidence of discolored roots were observed even with the susceptible cultivar 647A. These results suggest that a disease-forecast system based solely on inoculum densities of $V$. dahliae would be unreliable under field conditions when the other factors affecting the inoculum density-disease relationships cannot be controlled. Knowing the amount of initial inoculum may, however, save growers from planting horseradish in highly infested fields, but it would not guarantee a disease-free crop in fields with low levels of infestation.
\end{abstract}

Illinois leads the world in the production of horseradish, Armoracia rusticana P. Gaertn., B. Mey \& Scherb, with an average annual production estimated at 6 million $\mathrm{kg}$. The major area of production (approximately $500 \mathrm{ha}$ ) is located in the Mississippi River Valley, near East St. Louis, Illinois. The value of the horseradish crop depends on the quality of its white, fleshy, and pungent root used for the preparation of condiments for meats and seafood. Over the past two decades, a rootdiscoloration disease caused by Verticillium dahliae Kleb. $(11,17,22)$ has become one of the most important problems facing the horseradish growers in Illinois $(11,12)$. The extent of damage attributed to this disease has forced many growers to abandon what formerly were their most productive fields (11).

Attempts to control the disease by reducing inoculum densities of $V$. dahliae through crop rotation have not been successful due to the pathogen's extended host range (8) and ability to survive for long

Corresponding author: D. M. Eastburn

E-mail: eastburn@uiuc.edu

Accepted for publication 22 November 1999.

Publication no. D-2000-0121-03R

(C) 2000 The American Phytopathological Society periods of time in the absence of susceptible hosts (27). Fungicide treatment of planting stock and soil fumigation or solarization have been either ineffective or prohibitively expensive (17; D. M. Eastburn, unpublished). Horseradish cultivars with resistance to $V$. dahliae are not yet commercially available, although some sources of resistance were identified recently (5). Clearly, there is a pressing need for new approaches of managing the root discoloration disease of horseradish in the absence of effective control measures.

A disease forecast system based on an understanding of the relationship between inoculum densities of $V$. dahliae at the time of planting and the severity and incidence of root discoloration at harvest may assist growers in assessing the risk of the disease before planting horseradish in a particular field. The rationale of such a system lies on the observation that root discoloration of horseradish is a monocyclic disease, because the inoculum produced during a growing season, mostly microsclerotia, does not contribute to infection that same season. It seems reasonable, therefore, to believe that the severity and incidence of root discoloration would be related to inoculum densities of $V$. dahliae at the time of planting.

The relationship between inoculum densities of Verticillium spp. and the wilt diseases they cause has been investigated on a number of economically important crops, including cotton, Gossypium hirsutum L. $(2,3,7,10,21,23)$; tomato, Lycopersicon esculentum Mill. $(1,13)$; potato, Solanum tuberosum L. (9,19,20,25); and strawberry, Fragaria ananassa Duch. (14). On horseradish, Percich and Johnson (22) observed a positive correlation between inoculum densities of $V$. dahliae, up to 50 microsclerotia $(\mathrm{ms}) / \mathrm{g}$ of soil, and the percentage infection of roots, crowns, petioles, and leaves. Atibalentja and Eastburn (4) also found significant linear relationships between (log-transformed) inoculum densities of $V$. dahliae and a wilt-disease index. Both studies were conducted in the greenhouse. Our objective was to expand the scope of these two studies by investigating the relationship between inoculum densities of $V$. dahliae at the time of planting and the severity and incidence of root discoloration of horseradish at harvest in the greenhouse, microplots, and commercial production fields. Preliminary results have been reported (16).

\section{MATERIALS AND METHODS}

Greenhouse study. Root cuttings (sets) from a susceptible horseradish cultivar, 647A, were planted in a greenhouse in soil mixes that contained $0,1,5,10,25,50$, 100,200 , or $500 \mathrm{~ms} / \mathrm{g}$ of soil. The stock suspension of inoculum was prepared from equal proportions of microsclerotia from two horseradish isolates of $V$. dahliae, HR001 and HR015 (8), following standard procedures $(4,8,11)$. Specifically, 1-monthold potato-dextrose-agar (PDA) cultures of $V$. dahliae were blended with distilled water for $2 \mathrm{~min}$ at high speed in a Waring blender. The suspension was passed through a nested series of 250-, 180-, and $37-\mu \mathrm{m}$ sieves. Materials collected on the $37-\mu \mathrm{m}$ sieve were rinsed with tap water and resuspended in distilled water. The concentration of the suspension was determined by counting the number of microsclerotia with a hemacytometer before it was used to saturate sterile silica sand (U.S. Silica, Ottawa, IL). For the control treatment $(0 \mathrm{~ms} / \mathrm{g}$ of soil $)$, silica sand was saturated with distilled water. The saturated sand was air-dried at room temperature $\left(22\right.$ to $\left.24^{\circ} \mathrm{C}\right)$ for 3 days, and mixed with appropriate amounts of steam-sterilized potting mix (1:1:1, soil:sand:perlite) to obtain the desired inoculum densities of $V$. dahliae. Horseradish sets (25 cm long) were then planted in the soil mixtures in 
flats $(35$ by 50 by $10 \mathrm{~cm}$ ). An experimental unit consisted of one flat with three plants. The nine inoculum-density treatments were arranged in a randomized complete block design with four replications.

Plants were grown in the greenhouse for 3 months under natural light supplemented with 1,000-watt high-pressure sodium- and mercury-vapor lamps set to a 12-h/day photoperiod. Water was supplied as needed. At the end of the 3-month growth period, plants were harvested and rated for the severity of root discoloration symptoms on a 0 -to-5 scale, where $0=$ no vascular discoloration and $5=75$ to $100 \%$ of the root cross-section showing vascular discoloration (Fig. 1). The disease incidence was determined as the percentage of plants with
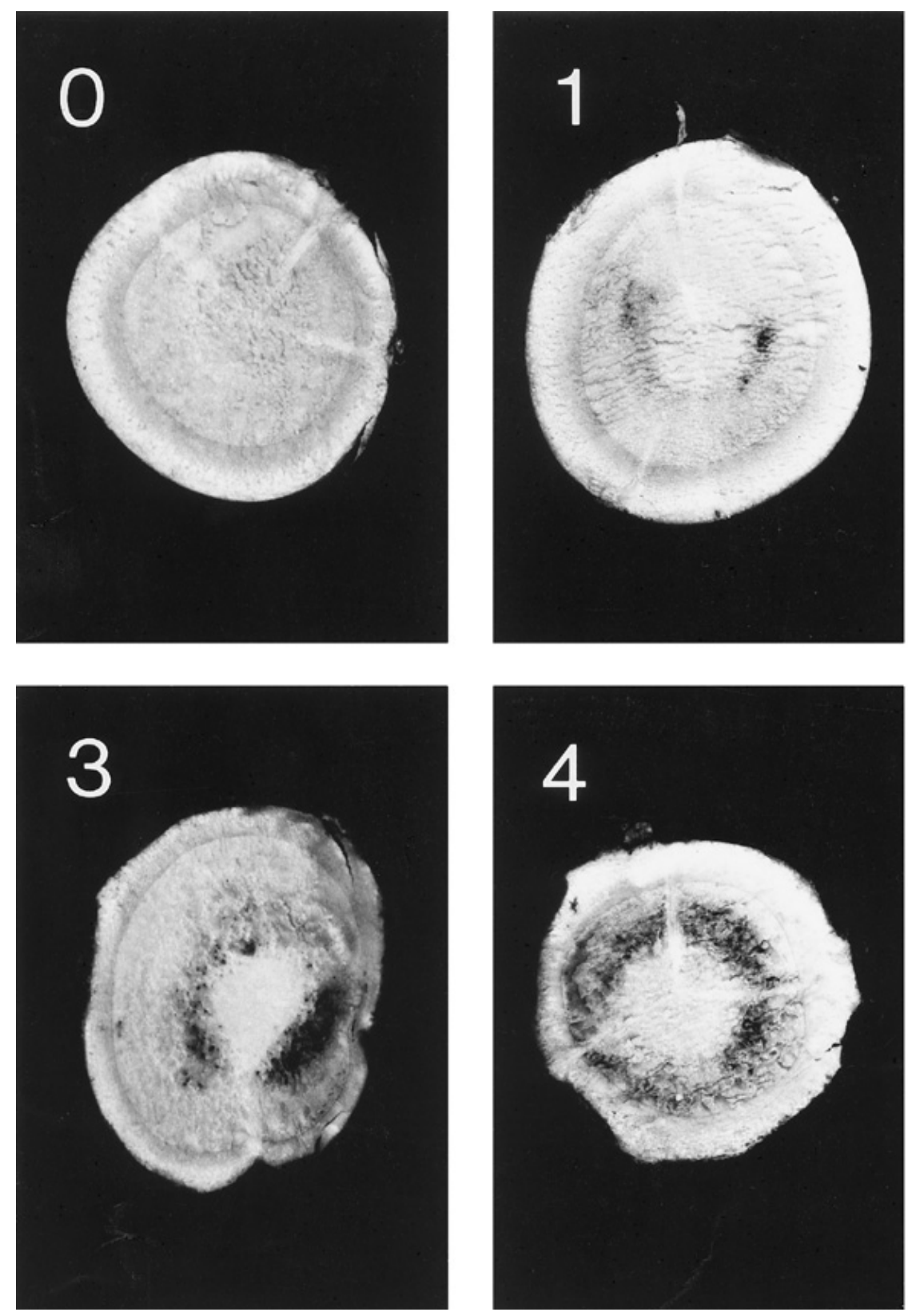

discolored roots in each experimental unit. The greenhouse experiment was repeated twice.

Microplot study. A total of $42 \mathrm{mi}-$ croplots $\left(1 \mathrm{~m}^{2}, 5 \mathrm{~m}\right.$ apart) were established in 1995 in the Pomology Research Farm at Urbana, Illinois. The top $0.35 \mathrm{~m}^{3}$ of soil from each microplot was removed and mixed with appropriate amounts of silica sand prepared as previously described to achieve final inoculum densities of $0,1,5$, $10,25,50$, or $100 \mathrm{~ms} / \mathrm{g}$ of soil. The soil mixtures were replaced in the original plots, and five sets of horseradish cv. 647A were planted in each microplot in June. The seven inoculum-density treatments were arranged in a randomized complete block design with six replications. At the end of the growing season, in November, plants were harvested and rated for the severity of root discoloration symptoms as outlined earlier. The microplot experiment was repeated in 1996 with five replications and a May planting date.

Field study. During the 1995 growing season, eight commercial production fields in the East St. Louis region were selected on the basis of their history of horseradish cropping and root discoloration. In each field, a study area (approximately $500 \mathrm{~m}^{2}$ ) was designated and divided into 10 blocks. The blocks consisted of two plots (4 by 6 $\mathrm{m})$, one of which was planted with four 10plant rows of horseradish cv. $647 \mathrm{~A}$, and the other was planted with four 10-plant rows of partially resistant horseradish cv. 769A.

Fig. 1. Rating scale for evaluating the severity of vascular discoloration of horseradish roots caused by Verticillium dahliae: $0=$ no vascular discoloration, $1=$ trace to less than $9 \%$ of the root cross-section show vascular discoloration, $2=10$ to less than $24 \%$ of the root cross-section show vascular discoloration, $3=25$ to less than $49 \%$ of the root cross-section show vascular discoloration, $4=50$ to less than $74 \%$ of the root cross-section show vascular discoloration, and $5=75$ to $100 \%$ of the root cross-section show vascular discoloration. 
The cultivars were randomly assigned to the plots within each block. Soon after planting in April, a soil sample consisting of 10 cores $(2.5 \mathrm{~cm}$ in diameter by $15 \mathrm{~cm}$ deep) was taken from each block following an X-pattern of sampling. The soil samples were air dried at room temperature for 2 weeks and $V$. dahliae inoculum densities were estimated as numbers of microsclerotia per gram of air-dried soil, using a modified wet-sieving procedure (15). Specifically, a 10-g subsample was taken from each soil sample and suspended in $200 \mathrm{ml}$ of distilled water containing 1\% Calgon (sodium carbonatel Benckiser Consumer Products, Inc., Danbury, CT) and $0.01 \%$ Tergitol NPX (Sigma-Aldrich, St. Louis, MO). After blending for $30 \mathrm{~s}$, the suspension was washed through a nested series of $250-, 180-$, and 37- $\mu \mathrm{m}$ sieves. The residues in the $37-\mu \mathrm{m}$ sieve were transferred to a centrifuge tube and pelleted for $5 \mathrm{~min}$ at $1,600 \times g$. Excess water was pipetted off before the pellet was resuspended in $10 \mathrm{ml}$ of sterile water, and $1 \mathrm{ml}$ of the suspension was spread onto each of 10 Petri dishes (100 by $15 \mathrm{~mm}$ ) of ethanol medium (6). The plates were dried in a laminar flow hood and incubated at 18 to $20^{\circ} \mathrm{C}$ in the dark for 1 to 2 weeks, at which time the plates were washed under a gentle stream of water and allowed to dry at room temperature for $24 \mathrm{~h}$. Colonies with microsclerotia were counted with the aid of a stereomicroscope.
At harvest, in November, five plants were randomly selected from each plot and rated for the severity of root discoloration symptoms as previously described. The experiment was repeated in 1996 in nine different commercial production fields in the East St. Louis area.

Statistical analysis. The data were subjected to covariance analyses (PROC MIXED, SAS Inc., Cary, NC) in which severity and incidence of root discoloration were the dependent variables; field, cultivar, and trial were the independent variables; and inoculum density was the covariate. Regression analyses (PROC REG, SAS Inc.) also were conducted when the trial $\times$ inoculum density interaction was significant and a unique model was not appropriate for all of the trials in the greenhouse and microplot experiments. Inoculum density was transformed to $\ln (x$ $+0.1)$ before the analysis of greenhouse and microplot data.

\section{RESULTS}

Symptoms of root discoloration were not observed on the non-inoculated horseradish plants in the greenhouse and microplot experiments. In contrast, most of the plants that were exposed to $V$. dahliae inoculum in the greenhouse and microplots showed symptoms of root discoloration. In the greenhouse, ratings of severity and incidence of discolored roots ranged from 0.3 \pm 0.1 (mean \pm standard error) and $33 \pm$
$14 \%$ with inoculum densities of $1 \mathrm{~ms} / \mathrm{g}$ of soil, to $4.6 \pm 0.2$ and $100 \%$ with $500 \mathrm{~ms} / \mathrm{g}$ of soil, respectively. A significant $(P<$ $0.05)$ trial $\times$ inoculum density interaction was observed in the greenhouse, because the response of horseradish to inoculum density varied from one trial to another. Specifically, the relationship between logtransformed inoculum densities and severity ratings was linear in the first trial (Fig. 2) but quadratic in the second and third trials (Figs. 3 and 4). In these latter two cases, the curves were concave downward in the second trial, but upward in the third; and their maximum and minimum of 4.4 and -0.5 , respectively, were reached with $3,827.5 \mathrm{~ms} / \mathrm{g}$ of soil $[\ln (x+0.1)=8.25]$ and $-0.1 \mathrm{~ms} / \mathrm{g}$ of soil $[\ln (x+0.1)=-4.30]$, which are outside the range of inoculum densities tested. Likewise, the relationship between log-transformed inoculum densities and incidence of discolored roots was best described by a quadratic (Fig. 2), a negative exponential (Fig. 3), and a linear function (Fig. 4) in the first, second, and third trials, respectively. The quadratic model estimated a maximum disease incidence of $103 \%$ with $202.3 \mathrm{~ms} / \mathrm{g}$ of soil $[\ln (x+0.1)=5.31]$, whereas the negative exponential model predicted that disease incidence rose from $91 \%$ with inoculum densities of $0.9 \mathrm{~ms} / \mathrm{g}$ of soil $[\ln (x+0.1)=$ $0]$ and steadily approached an asymptotic maximum of $102 \%$ as inoculum densities increased.

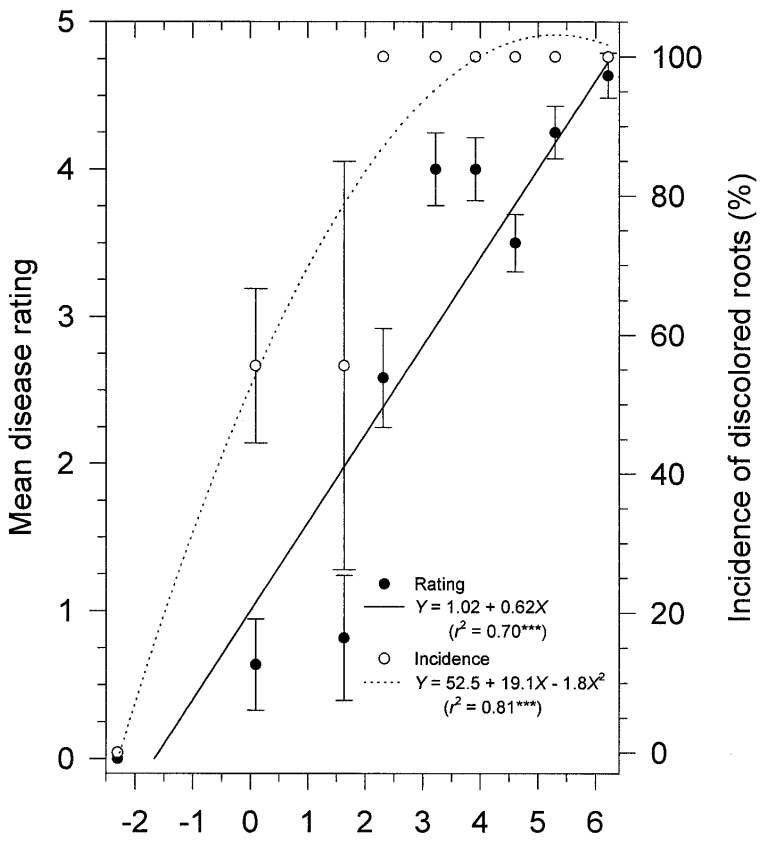

Inoculum density [In(microsclerotia/g soil + 0.1)]

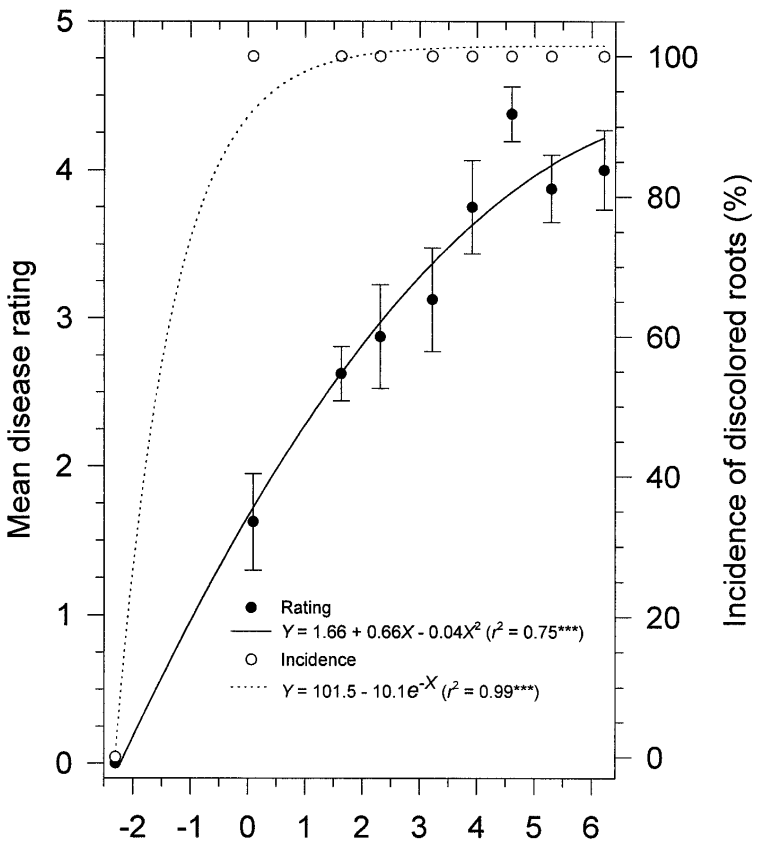

Inoculum density [In(microsclerotia/g soil + 0.1)]
Fig. 2. Relationship between inoculum density of Verticillium dahliae and ratings of severity and incidence of discolored horseradish roots in the first greenhouse trial. The severity of root discoloration was rated on a 0 -to- 5 scale in which $0=$ no vascular discoloration and $5=75$ to $100 \%$ of the root cross-section show vascular discoloration. Each data point stands for the mean of four replications of three plants each, bars represent standard errors, and asterisks indicate significance at $P=0.001$.
Fig. 3. Relationship between inoculum density of Verticillium dahliae and ratings of severity and incidence of discolored horseradish roots in the second greenhouse trial. The severity of root discoloration was rated on a 0 -to 5 scale in which $0=$ no vascular discoloration and $5=75$ to $100 \%$ of the root cross-section show vascular discoloration. Each data point stands for the mean of four replications of three plants each, bars represent standard errors, and asterisks indicate significance at $P=0.001$. 
In microplots, ratings of severity and incidence of discolored roots ranged from $0.2 \pm 0.1$ and $17 \pm 17 \%$ with $1 \mathrm{~ms} / \mathrm{g}$ of soil, to $4.1 \pm 0.2$ and $100 \%$ with $100 \mathrm{~ms} / \mathrm{g}$ of soil, respectively. Host response to inoculum densities of $V$. dahliae also varied with trials. Thus, the relationship between logtransformed inoculum densities and severity ratings was linear in the first trial (Fig. 5) but quadratic in the second (Fig. 6). In the latter case, the predicted maximum severity rating of 3.8 was reached with $128.9 \mathrm{~ms} / \mathrm{g}$ of soil $[\ln (x+0.1)=4.86]$, which is outside the range of inoculum densities tested in microplots. Similarly, the relationship between log-transformed inoculum densities and incidence of discolored roots followed a linear trend in the first trial (Fig. 5) but a negative exponential in the second (Fig. 6). According to the latter model, the incidence of discolored roots rose from $88 \%$ with inoculum densities of $0.9 \mathrm{~ms} / \mathrm{g}$ of soil $[\ln (x+0.1)=0]$ and asymptotically approached a maximum of 98\% as inoculum densities increased.

Root discoloration of horseradish and its causal agent, $V$. dahliae, were present in all of the 17 fields investigated. On average, inoculum densities of $V$. dahliae ranged from $0.2 \pm 0.2$ (mean \pm standard deviation) to $39.2 \pm 12.5 \mathrm{~ms} / \mathrm{g}$ of soil; and severity ratings ranged from $0.1 \pm 0.1$ to $3.7 \pm 0.4$ for susceptible cv. 647A, and from $0.0 \pm$ 0.0 to $3.1 \pm 0.5$ for partially resistant $\mathrm{cv}$. 769A (Table 1). The incidence of discol- ored roots varied from $7 \% \pm 10$ to $100 \% \pm$ 0 and from $0 \pm 0$ to $98 \pm 6$ for cvs. 647A and 769A, respectively. No correlation was found between inoculum densities of $V$. dahliae and ratings of severity and incidence of root discoloration in the field study (Fig. 7). In some fields with low inoculum densities, high ratings of severity and incidence of discolored roots were observed even with partially resistant cv. 769A (Table 1 and Fig. 7). Conversely, in other fields with high inoculum densities, low ratings of severity and incidence of discolored roots were observed even with susceptible cv. 647A. A significant $(P<$ $0.05)$ cultivar $\times$ field interaction was observed, because the responses of the two cultivars differed in some fields but not in others (Table 1). The cultivar $\times$ year interaction also was significant, because susceptible cv. 647A had more disease than partially resistant cv. 769A in both years, except for the 1996 incidence of discolored roots, but the differences varied in magnitude between the two years.

\section{DISCUSSION}

In this study, inoculum density-disease (ID-D) relationships between $V$. dahliae and horseradish were investigated in greenhouse, microplot, and commercial production fields. The purpose was to develop a disease-forecast system based on an understanding of the relationships between inoculum density of $V$. dahliae at the time of planting and the severity and incidence of root discoloration of horseradish at harvest. The results indicate that ID-D relationships were stronger in the greenhouse $\left(r^{2}\right.$ ranged from 0.70 to 0.75 and from 0.81 to 0.99 for severity and incidence of discolored roots, respectively) than in microplots $\left(r^{2}\right.$ ranged from 0.36 to 0.50 and from 0.48 to 0.93 for severity and incidence of discolored roots, respectively), but were not apparent in the commercial production fields. These results most likely reflect the loss of control, as the study moved from the greenhouse to the field, over the various factors known to affect ID-D relationships between Verticillium spp. and their hosts. Those factors include the soil type, moisture, temperature, $\mathrm{pH}$, cultural practices, pathogen strains, spatial distribution of inoculum, physiology of individual plants, and interactions with other microorganisms $(1,2,7,9,10,14,19,21,23,24)$. In the greenhouse, competition from other microorganisms was minimized by using steamsterilized soil; inoculum originated from well-characterized strains of the pathogen and was uniformly mixed in the soil; and temperature and moisture were controlled. In contrast, inoculum was the only factor controlled in microplots, and neither the inoculum nor the environmental conditions were controlled in the field. In addition, while inoculum density of $V$. dahliae was determined by direct counts of microscle-

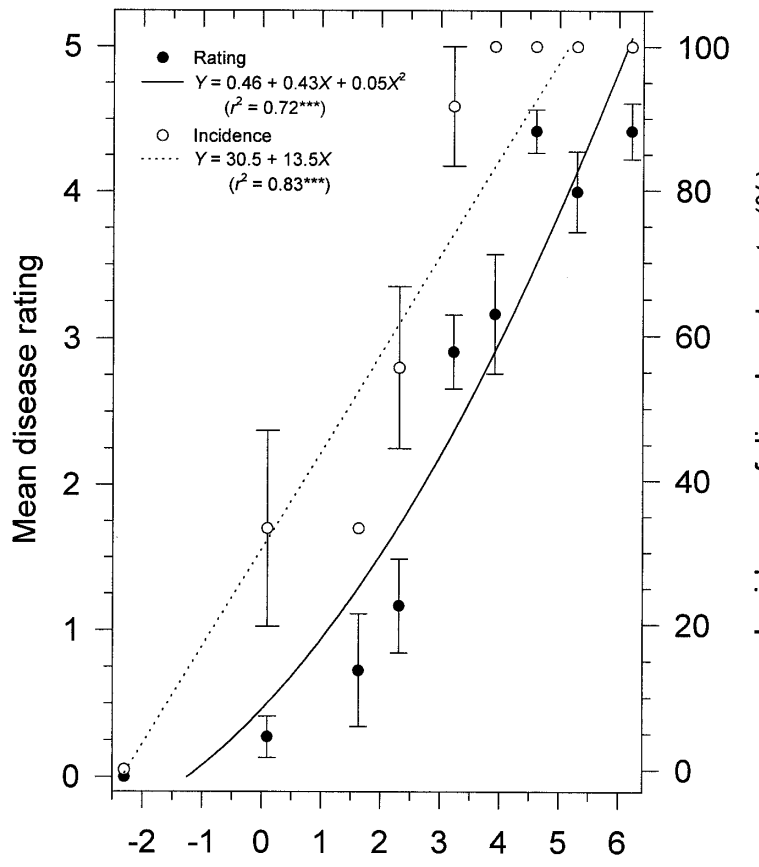

Inoculum density [In(microsclerotia/g soil + 0.1)]

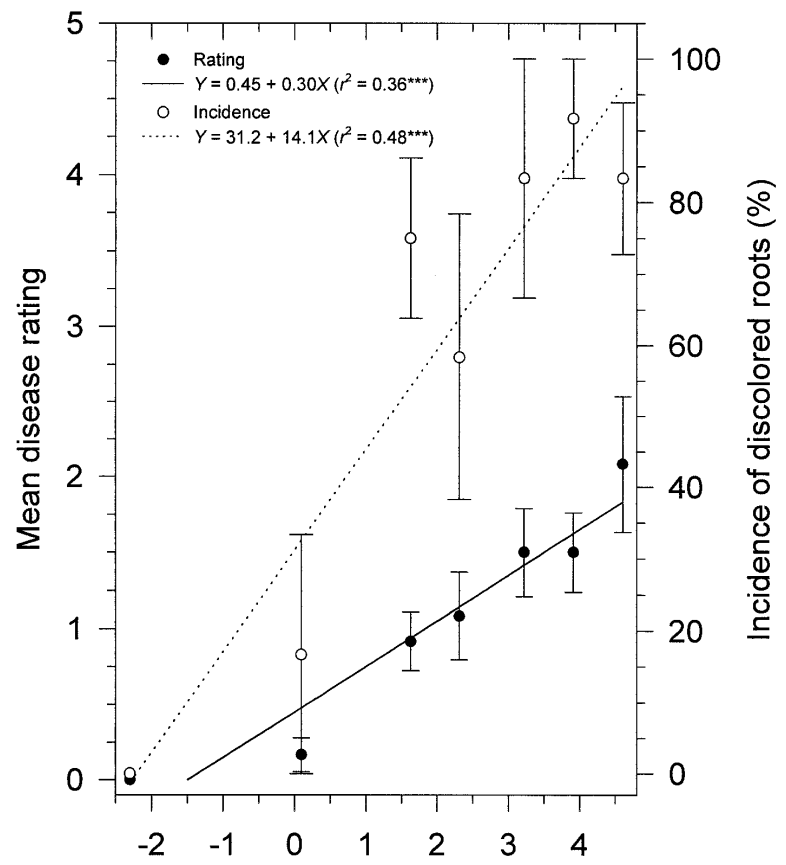

Inoculum density [In(microsclerotia/g soil + 0.1)]
Fig. 4. Relationship between inoculum density of Verticillium dahliae and ratings of severity and incidence of discolored horseradish roots in the third greenhouse trial. The severity of root discoloration was rated on a 0 -to- 5 scale in which $0=$ no vascular discoloration and $5=75$ to $100 \%$ of the root cross-section show vascular discoloration. Each data point stands for the mean of four replications of three plants each, bars represent standard errors, and asterisks indicate significance at $P=0.001$.
Fig. 5. Relationship between inoculum density of Verticillium dahliae and ratings of severity and incidence of discolored horseradish roots in the first microplot trial. The severity of root discoloration was rated on a 0 -to- 5 scale in which $0=$ no vascular discoloration and $5=75$ to $100 \%$ of the root cross-section show vascular discoloration. Each data point stands for the mean of six replications of five plants each, bars represent standard errors, and asterisks indicate significance at $P=0.001$. 


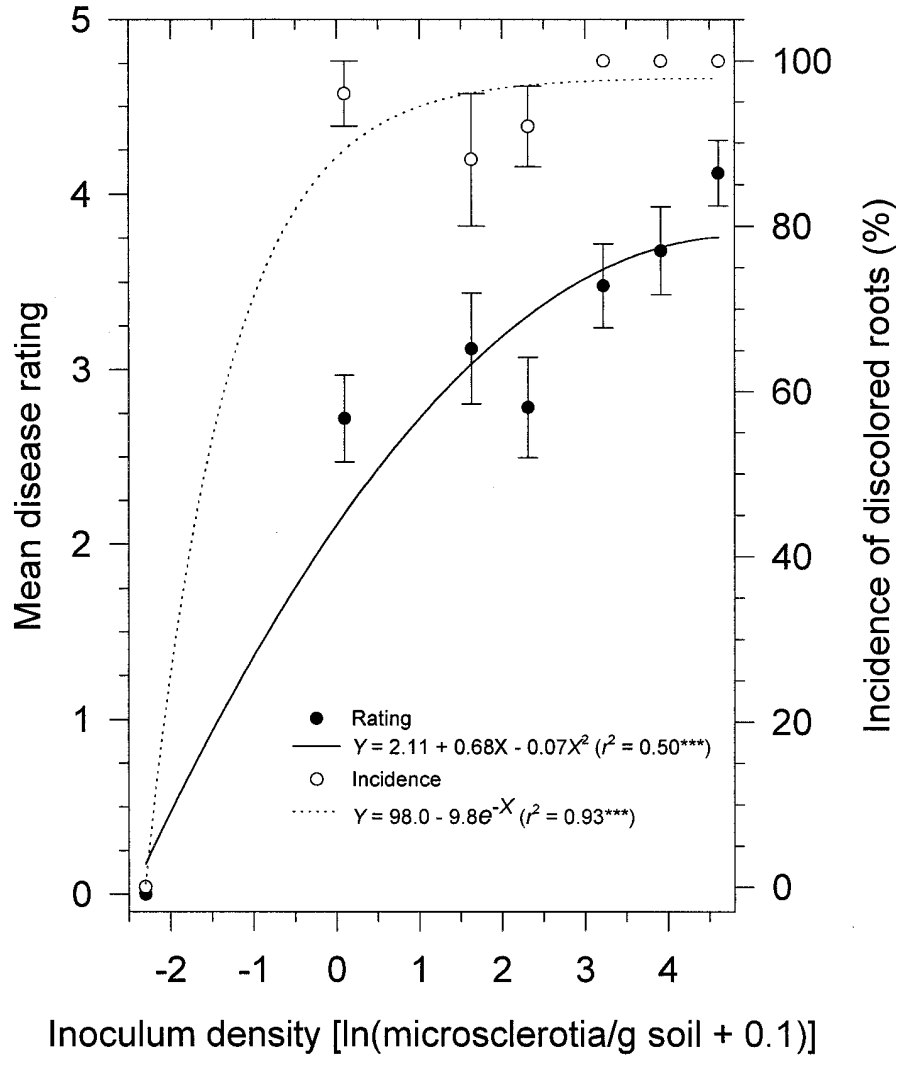

Fig. 6. Relationship between inoculum density of Verticillium dahliae and ratings of severity and incidence of discolored horseradish roots in the second microplot trial. The severity of root discoloration was rated on a 0 -to- 5 scale in which $0=$ no vascular discoloration and $5=75$ to $100 \%$ of the root crosssection show vascular discoloration. Each data point stands for the mean of five replications of five plants each, bars represent standard errors, and asterisks indicate significance at $P=0.001$. rotia added to the soil in the greenhouse and microplots, the wet-sieving method used to estimate inoculum density in the field can only detect propagules that fit specific size characteristics $(15,18)$.

Both linear and curvilinear (quadratic and negative exponential) relationships between inoculum density of $V$. dahliae and ratings of severity and incidence of discolored roots of horseradish were observed in the greenhouse and microplot studies. Similar results have been reported on horseradish $(4,22)$ and other Verticillium hosts $(2,3,13,14,19,21,23,29)$. Interestingly, natural occurrence of curvilinear ID-D relationships involving $V$. dahliae has been confirmed by results from field surveys $(21,23,29)$, thus refuting Vanderplank's assertion that such curves are artifacts (26). Also consistent with published data is the lack of correlation between inoculum density of $V$. dahliae and the severity and incidence of discolored roots of horseradish in commercial production fields. Although significant ID-D relationships have been described in several field studies $(2,3,13,14,19,21,23,29)$, instances do exist where no correlation was found between inoculum density of $V$. dahliae and the severity and incidence of wilt diseases caused by this fungus $(1,7,10,13,21)$. As mentioned earlier, inconsistencies between inoculum density of Verticillium spp. and the amount of disease inflicted to field crops have been attributed to the numerous other factors affecting ID-D rela-

Table 1. Inoculum densities (microsclerotia per gram of air-dried soil) of Verticillium dahliae, severity rating, and incidence of discolored roots of two horseradish cultivars (647A, susceptible, and 769A, moderately resistant) in 17 commercial production fields surveyed in 1995 and 1996 in the East St. Louis, Illinois, $\operatorname{area}^{\mathrm{x}}$

\begin{tabular}{|c|c|c|c|c|c|c|c|}
\hline \multirow[b]{2}{*}{ Year, field } & \multirow[b]{2}{*}{ Inoculum } & \multicolumn{3}{|c|}{ Severity rating $^{y}$} & \multicolumn{3}{|c|}{ Incidence $(\%)$} \\
\hline & & 647A & 769A & Mean & $647 A$ & 769A & Mean \\
\hline \multicolumn{8}{|l|}{1995} \\
\hline 1 & 34.3 & $3.4 \mathrm{aA}^{\mathrm{z}}$ & $2.1 \mathrm{bcB}$ & 2.8 & $100 \mathrm{aA}$ & $84 \mathrm{bB}$ & 92 \\
\hline 2 & 1.0 & $3.4 \mathrm{aA}$ & $2.1 \mathrm{bcB}$ & 2.8 & $100 \mathrm{aA}$ & $82 \mathrm{bB}$ & 91 \\
\hline 3 & 6.3 & $0.2 \mathrm{eA}$ & $0.0 \mathrm{gA}$ & 0.1 & $18 \mathrm{deA}$ & $2 \mathrm{fB}$ & 10 \\
\hline 4 & 3.8 & $0.2 \mathrm{eA}$ & $0.0 \mathrm{gA}$ & 0.1 & $10 \mathrm{eA}$ & $4 \mathrm{fA}$ & 7 \\
\hline 5 & 0.2 & $0.1 \mathrm{eA}$ & $0.0 \mathrm{gA}$ & 0.0 & $7 \mathrm{eA}$ & $0 \mathrm{fA}$ & 3 \\
\hline 6 & 2.3 & $0.8 \mathrm{cdA}$ & $0.1 \mathrm{gB}$ & 0.4 & $40 \mathrm{cA}$ & $4 \mathrm{fB}$ & 22 \\
\hline 7 & 10.1 & $3.6 \mathrm{aA}$ & $3.1 \mathrm{aB}$ & 3.4 & $100 \mathrm{aA}$ & $98 \mathrm{aA}$ & 99 \\
\hline 8 & 2.0 & $0.2 \mathrm{eA}$ & $0.0 \mathrm{gA}$ & 0.1 & $18 \mathrm{deA}$ & $0 \mathrm{fB}$ & 9 \\
\hline Mean & 7.5 & $1.5 \alpha \mathrm{A}$ & $0.9 \alpha \mathrm{B}$ & 1.2 & $49 \alpha \mathrm{A}$ & $34 \alpha \mathrm{B}$ & 42 \\
\hline \multicolumn{8}{|l|}{1996} \\
\hline 9 & 39.2 & $0.6 \mathrm{dA}$ & 0.7 efA & 0.7 & $28 \mathrm{cdA}$ & $36 \mathrm{cdA}$ & 32 \\
\hline 10 & 0.5 & $2.9 \mathrm{bA}$ & $2.5 \mathrm{bB}$ & 2.7 & $98 \mathrm{aA}$ & $96 \mathrm{abA}$ & 97 \\
\hline 11 & 1.8 & $2.7 \mathrm{bA}$ & $1.6 \mathrm{~dB}$ & 2.2 & $96 \mathrm{aA}$ & 88 abA & 92 \\
\hline 12 & 8.4 & $0.3 \mathrm{de} A$ & $0.5 \mathrm{fg} A$ & 0.4 & $24 \mathrm{cdA}$ & $26 \mathrm{deA}$ & 25 \\
\hline 13 & 14.1 & $3.7 \mathrm{aA}$ & $2.0 \mathrm{cB}$ & 2.9 & $100 \mathrm{aA}$ & $90 \mathrm{abA}$ & 95 \\
\hline 14 & 25.0 & $0.2 \mathrm{deA}$ & $0.3 \mathrm{fg} \mathrm{A}$ & 0.3 & $18 \mathrm{deA}$ & $22 \mathrm{eA}$ & 20 \\
\hline 15 & 1.7 & $1.2 \mathrm{cA}$ & $1.0 \mathrm{eA}$ & 1.1 & $58 \mathrm{bA}$ & $48 \mathrm{cA}$ & 53 \\
\hline 16 & 5.2 & $0.3 \mathrm{deA}$ & $0.2 \mathrm{gA}$ & 0.3 & $24 \mathrm{cdA}$ & 16 efA & 20 \\
\hline 17 & 8.4 & $0.4 \mathrm{deA}$ & $1.1 \mathrm{eB}$ & 0.7 & $17 \mathrm{de} A$ & $43 \mathrm{cB}$ & 30 \\
\hline Mean & 11.6 & $1.4 \alpha \mathrm{A}$ & $1.1 \beta \mathrm{B}$ & 1.2 & $51 \alpha \mathrm{A}$ & $52 \beta A$ & 52 \\
\hline Grand mean & 9.7 & 1.4 & 1.0 & 1.2 & 50 & 43 & 47 \\
\hline
\end{tabular}

${ }^{x}$ Figures are means of 10 replications of five plants each.

y The severity of vascular discoloration of horseradish roots was rated on a 0 -to- 5 scale in which $0=$ no vascular discoloration and $5=75$ to $100 \%$ of the root cross-section show vascular discoloration.

${ }^{z}$ Roman and Greek letters are used to describe the field $\times$ cultivar and year $\times$ cultivar interactions, respectively. In the first case, lowercase letters serve to compare fields within a cultivar and capital letters are for comparing cultivars within a field. In the second case, lowercase letters compare years within a cultivar and capital letters compare cultivars within a year. In any comparison, figures followed by the same letter are not significantly different $(P \geq$ 0.05 ) according to the $t$ test. 


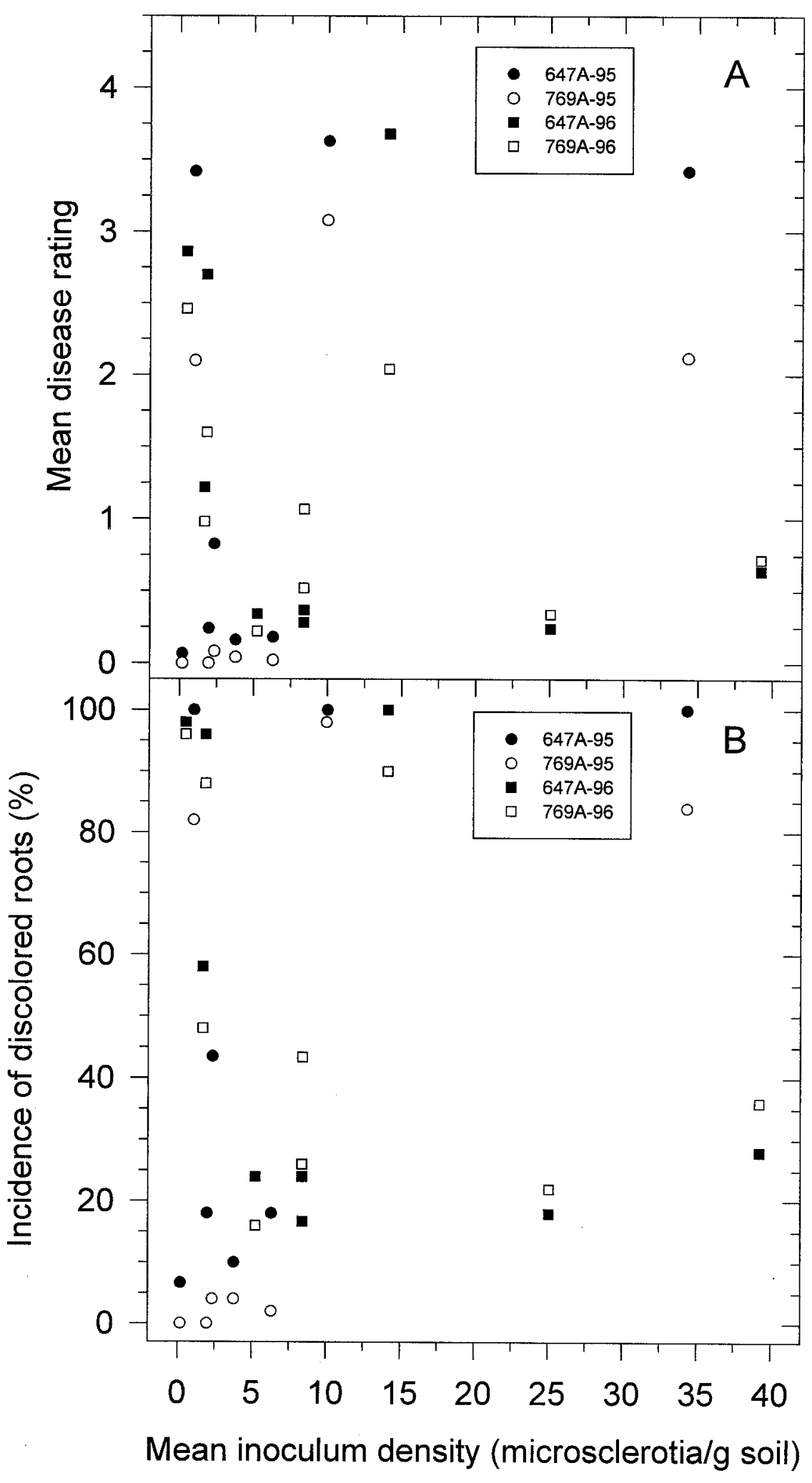

Fig. 7. Lack of relationship between inoculum density of Verticillium dahliae and ratings of (A) severity and (B) incidence of discolored roots of two horseradish cultivars $(647 \mathrm{~A}$, susceptible, and 769A, partially resistant) in 17 commercial production fields surveyed in 1995 and 1996 in the East St. Louis, Illinois, area. The severity of root discoloration was rated on a 0 -to-5 scale in which $0=$ no vascular discoloration and $5=75$ to $100 \%$ of the root cross-section show vascular discoloration. Each data point stands for the mean of 10 replications of five plants each. tionships between those pathogens and their hosts $(1,2,7,9,10,13,14,19,21,23,24)$. In Britain, for example, Verticillium wilt of strawberry was more severe on light and sandy soils than on heavier soils (14). In potato, cultural management practices accounted for as much as $71 \%$ of the field variability in relation to the colonization of the stem tissue by $V$. dahliae (9). Synergetic interactions between this fungal pathogen and the nematode Pratylenchus penetrans also have been associated with the potato early dying disease (24). In cotton (7) and in tomato (13), the influence of inoculum density on Verticillium wilt varied with the strains of the pathogen and the host genotype. Soil sampling patterns and assay techniques also affect the accuracy with which inoculum density is determined, inasmuch as microsclerotia of $V$. dahliae are not randomly distributed in field soil and the soil assay procedures in common use differ in their efficiency to recover $V$. dahliae propagules from soil $(15,18,25,28)$. It is not clear which of the above-mentioned factors were involved in the present study. Regardless of the causes, however, the inconsistency between inoculum densities of $V$. dahliae and the severity and incidence of discolored roots of horseradish in commercial production fields indicates that a forecast system based solely on inoculum densities would be unreliable. At best, such a system could help growers avoid planting horseradish in fields with high inoculum densities of $V$. dahliae, but it would not guarantee a disease-free crop in fields with low inoculum densities.

\section{ACKNOWLEDGMENTS}

We thank the Horseradish Growers Association for providing the fields used in this study; and J. K. Pataky, Department of Crop Sciences, for his insightful suggestions during the preparation of the manuscript.

\section{LITERATURE CITED}

1. Ashworth, L. J., Jr., Huisman, O. C., Harper, D. M., and Stromberg, L. K. 1979. Verticillium wilt disease of tomato: Influence of inoculum density and root extension upon disease severity. Phytopathology 69:490-492.

2. Ashworth, L. J., Jr., Huisman, O. C., Harper, D. M., Stromberg, L. K., and Bassett, D. M. 1979. Verticillium wilt disease of cotton: Influence of inoculum density in the field. Phytopathology 69:483-489.

3. Ashworth, L. J., Jr., McCutcheon, O. D., and George, A. G. 1972. Verticillium albo-atrum: The quantitative relationship between inoculum density and infection of cotton. Phytopathology 62:901-903.

4. Atibalentja, N., and Eastburn, D. M. 1997. Evaluation of inoculation methods for screening horseradish cultivars for resistance to Verticillium dahliae. Plant Dis. 81:356-362.

5. Atibalentja, N., and Eastburn, D. M. 1998. Verticillium dahliae resistance in horseradish germ plasm from the University of Illinois collection. Plant Dis. 82:176-180.

6. Ausher, R., Katan, J., and Ovadia, S. 1975. An improved selective medium for the isolation of Verticillium dahliae. Phytoparasitica 3:133-137.

7. Bejarano-Alcazar, J., Melero-Vara, J. M., 
Blanco-Lopez, M. A., and Jimenez-Diaz, R. M. 1995. Influence of inoculum density of defoliating and non-defoliating types of Verticillium dahliae on epidemics of Verticillium wilt of cotton in Southern Spain. Phytopathology 85:1474-1481.

8. Chang, R. J., and Eastburn, D. M. 1994. Host range of Verticillium dahliae from horseradish and pathogenicity of strains. Plant Dis. 78:503-506.

9. Davis, J. R., and Everson, D. O. 1986. Relation of Verticillium dahliae in soil and potato tissue, irrigation method, and $\mathrm{N}$-fertility to Verticillium wilt of potato. Phytopathology 76:730-736.

10. DeVay, J. E., Forrester. L. L., Garber, R. H., and Butterfield, E. J. 1974. Characteristics and concentration of propagules of Verticillium dahliae in air-dried field soils in relation to the prevalence of Verticillium wilt in cotton. Phytopathology 64:22-29.

11. Eastburn, D. M., and Chang, R. J. 1994. Verticillium dahliae: A causal agent of root discoloration of horseradish in Illinois. Plant Dis. 78:496-498.

12. Gerber, J. M., Doll, C. C., Simons, R. K., and Fillingim, K. E. 1983. Internal discoloration of horseradish-development of symptoms. Univ. Ill. Veg. Res. Rep. Hortic. Ser. 47:34-37.

13. Grogan, R. G., Ioannou, N., Schneider, R. W., Sall, M. A., and Kimble, K. A. 1979. Verticillium wilt on resistant tomato cultivars in California: Virulence of isolates from plants and soil and relationship of inoculum density to disease incidence. Phytopathology 69:1176-
1180.

14. Harris, D. C., and Yang, J. R. 1996. The relationship between the amount of Verticillium dahliae in soil and the incidence of strawberry wilt as a basis for disease risk prediction. Plant Pathol. 45:106-114.

15. Huisman, O. C., and Ashworth, L. J., Jr. 1974 Quantitative assessment of Verticillium alboatrum in field soils: Procedural and substrate improvements. Phytopathology 64:10431044.

16. Khan, A., and Eastburn, D. M. 1996. Influence of inoculum density of Verticillium dahliae on horseradish root discoloration. (Abstr.) Phytopathology 86:S84.

17. Mueller, J. P., Percich, J. A., and Mitchell, J. E. 1982. Root deterioration associated with Verticillium wilt of horseradish. Plant Dis. 66:410-414.

18. Nicot, P. C., and Rouse, D. I. 1987. Precision and bias of three quantitative soil assays for Verticillium dahliae. Phytopathology 77:875881.

19. Nicot, P. C., and Rouse, D. I. 1987. Relationship between soil inoculum density of Verticillium dahliae and systemic colonization of potato stems in commercial fields over time. Phytopathology 77:1346-1355.

20. Nnodu, E. C., and Harrison, M. D. 1979. The relationship between Verticillium albo-atrum inoculum density and potato yield. Am. Potato J. 56:11-25.

21. Paplomatas, E. J., Bassett, D. M., Broome, J. C., and DeVay, J. E. 1992. Incidence of Verticillium wilt and yield losses of cotton culti- vars (Gossypium hirsutum) based on soil inoculum density of Verticillium dahliae. Phytopathology 82:1417-1420.

22. Percich, J. A., and Johnson, D. R. 1990. A root rot complex of horseradish. Plant Dis. 74:391-393.

23. Pullman, G. S., and DeVay, J. E. 1982. Epidemiology of Verticillium wilt of cotton: A relationship between inoculum density and disease progression. Phytopathology 72:549554.

24. Rowe, R. C., Riedel, R. M., and Martin, M. J. 1985. Synergistic interactions between Verticillium dahliae and Pratylenchus penetrans in potato early dying disease. Phytopathology 75:412-418.

25. Smith, V. L., and Rowe, R. C. 1984. Characteristics and distribution of propagules of Verticillium dahliae in Ohio potato field soils and assessment of two assay methods. Phytopathology 74:553-556.

26. Vanderplank, J. E. 1975. Principles of plant infection. Academic Press, New York.

27. Wilhelm, S. 1955. Longevity of the Verticillium wilt fungus in the laboratory and field. Phytopathology 45:180-181.

28. Xiao, C. L., Hao, J. J., and Subbarao, K. V. 1997. Spatial patterns of microsclerotia of Verticillium dahliae in soil and Verticillium wilt of cauliflower. Phytopathology 87:325-331

29. Xiao, C. L., and Subbarao, K. V. 1998. Relationship between Verticillium dahliae inoculum density and wilt incidence, severity, and growth of cauliflower. Phytopathology $88: 1108-1115$. 